\title{
Urinary Lipocalin Protein in a Female Rodent with Correlation to Phases in the Estrous Cycle: An Experimental Study Accompanied by In Silico Analysis
}

\author{
Subramanian Muthukumar ${ }^{1,29}$, Durairaj Rajesh ${ }^{19}$, Ganesan Saibaba ${ }^{1}$, Alagersamy Alagesan ${ }^{1}$, \\ Rengasamy Lakhsminarayanan Rengarajan ${ }^{1}$, Govindaraju Archunan ${ }^{1}$ *
}

1 Centre for Pheromone Technology, Department of Animal Science, School of Life Sciences, Bharathidasan University, Tiruchirappalli, India, 2 The Swire Institute of Marine Science and School of Biological Sciences, The University of Hong Kong, Hong Kong, SAR

\begin{abstract}
Male urinary lipocalin family proteins, practically odorant-binding proteins but also could be pheromones by themselves, in rodents act as a shuttle for chemosignal communication and facilitate delivery of the signals for access to congeners. However, presence of this protein in urine of female rodents has not yet been reported. Therefore, the present investigation was carried out to find if lipocalin family protein is present in the urine of female house rat and, if so, to find whether its expression differs between the phases in the estrous cycle. The rat urinary protein was separated in single dimensional gel electrophoresis. A $14.5 \mathrm{kDa}$ lipocalin protein appeared in the urine prominently during the estrus and metestrus phases compared to proestrus and diestrus phases. The expression of this protein in the urine was very low in ovariectomized rats. MALDI-TOF/MS analysis affirmed the $14.5 \mathrm{kDa}$ protein as a lipocalin family protein. Analysis adopting bio-informatics tools further proved the protein as a lipocalin family member. Thus, this study for the first time demonstrated the presence of a lipocalin family protein in the urine of a female rodent and it was highly expressed during estrus phase. This lipocalin protein in female rat urine may facilitate a chemosignal function independently of a pheromone or in association with a specific pheromone.
\end{abstract}

\author{
Citation: Muthukumar S, Rajesh D, Saibaba G, Alagesan A, Rengarajan RL, et al. (2013) Urinary Lipocalin Protein in a Female Rodent with Correlation to Phases in \\ the Estrous Cycle: An Experimental Study Accompanied by In Silico Analysis. PLoS ONE 8(8): e71357. doi:10.1371/journal.pone.0071357 \\ Editor: Hiroaki Matsunami, Duke University, United States of America \\ Received March 15, 2013; Accepted June 30, 2013; Published August 14, 2013 \\ Copyright: (c) 2013 Muthukumar et al. This is an open-access article distributed under the terms of the Creative Commons Attribution License, which permits \\ unrestricted use, distribution, and reproduction in any medium, provided the original author and source are credited. \\ Funding: The authors have no support or funding to report. \\ Competing Interests: The authors have declared that no competing interests exist. \\ * E-mail: archunan@bdu.ac.in \\ 9 These authors contributed equally to this work.
}

\section{Introduction}

Chemosignals are small volatile compounds associated in one or more ways in synchronization of aspects of reproductive physiology between males and females and mediation of social responses $[1,2]$. Rodents excrete large amounts of proteins in their urine which play a significant role in the delivery of chemical messages $[3,4]$. The volatile urinary compounds of mouse bind with carrier proteins called major urinary proteins (MUPs) [3]. A comparable functional protein, $\alpha-2 \mathrm{u}$ globulin, has been identified in the rat [5]. Both MUPs and $\alpha-2 u$ globulin belong to the structural homology superfamily called lipocalin [6,7]. A variety of small volatile molecules present in the male mouse urine (brevicomin, thiazole) bind with the MUPs and produce wide-ranging effects in the conspecifics $[8,9,10]$. Furthermore, it has been demonstrated that MUP-pheromone binding in male mice urine provides for a gradual release of the volatile ligand to the environment [11] thereby enhancing the longevity of the volatile. This finding provides strong circumstantial evidence that the lipocalin (MUP) is capable of releasing the volatiles at a slow pace, suggesting a lead to a biological application. Similarly, in the urine of male rat a volatile was found in a form bound to $\alpha-2 \mathrm{u}$ globulin [12], and pheromone- $\alpha-2 \mathrm{u}$ globulin binding was also traced to the preputial gland which is one of the major sources of volatiles [5]. Thus, the lipocalin proteins present in the male possess the ability to bind and release the volatiles and participate in several pheromonebased effects in the conspecifics.

Looking for a role for the urinary lipocalin proteins in male rodents, it has been shown that the proteins by themselves might act as pheromones or associate with specific volatiles so as to release them in small quanta and bring about pheromonal effects on the conspecifics. The MUP, along with its bound volatile, has been found to be involved in several primer pheromonal effects including male-induced pregnancy block (Bruce effect) and acceleration of puberty (Vandenbergh effect) in female mice $[13,14]$. Aphrodisin, a lipocalin present in hamster vaginal discharge, acts as a reproductive pheromone [15]. A low molecular weight involatile protein darcin, identified in male mouse urine, has been found to act as a male sex pheromone and attract female mice [16].

Analysis of the chemosignal-binding protein at the levels of primary and tertiary structures in relation to the lipocalin family proteins strongly suggested that the chemosignal-binding proteins belong to the lipocalin family [17]. The tertiary structure of MUPs expounds hydrophobic residues which would provide for ligandbinding ability and protein stability [18]. The $2.4 \AA$ crystal structure, a conserved $\beta$-barrel structure, in MUP-I isolated from mouse urine [6] indicates that MUPs are members of the lipocalin 
family protein [19]. Crystal structures have been determined for several other lipocalins, including serum retinol-binding protein [20], $\beta$-lactoglobulin [21], bilin-binding protein [22], and $\alpha-2 u$ globulin [6].

During estrous cycle, the females differ in physiological status and hormonal regulation, which would influence their chemical cues for the attraction towards the partner. During estrus, a specific volatile signal would pass from female to male partner through urine as a mating call, in which the lipocalin protein may play role as a chemosignal shuttle [23]. Estrus-specific chemosignals have been reported in the urine of rat [24], mouse [25], cow [26,27], buffalo [28,29] and elephant [30]. However, even though there are well documented studies on lipocalin protein in the urine of male rodents, there is no specific report on presence of lipocalin proteins in urine of female rodent. Therefore, we undertook this study to find the presence of lipocalin protein in commensal rat urine and to perceive their expressional difference with reference to the estrous cycle.

\section{Materials and Methods}

\section{Ethics Statement}

The procedures used in the present study were approved by the Institutional Animal Ethics Committee (IAEC) of Bharathidasan University, India, under the regulatory control of Committee for the Purpose of Control Supervision on Experiments on Animals (CPCSEA), Government of India (Approval No. BDU/IAEC/
2012/61) and the rats were maintained at the animal house facility, Department of Animal Science, Bharathidasan University, Tiruchirappalli, India.

\section{Experimental Animals}

The rat species used in the present study, commensal rat (Rattus rattus), is not included in the list of endangered/protected animals. The rats were trapped at residential areas close to Bharathidasan University, with proper permission from the house owners. All animals thus collected were transferred to the animal house maintained by Department of Animal Science, Bharathidasan University, India. Reproductively active female rats weighing $\sim 150-200 \mathrm{~g}$ were selected and allowed to acclimate to laboratory conditions for one month. After laboratory acclimation, animals with regular estrous cycle were selected for further experimental study. The rats were housed in polypropylene cages $(40 \times 25 \times 15)$ with $2 \mathrm{~cm}$ of rice husk lining the bottom as bedding material. The bedding material was changed once every three days to maintain the hygienic condition. All animals were maintained in 12:12 L \& D cycle throughout the experimental period.

\section{Determination of Phases of Estrous Cycle}

For identification of the phases of estrous cycle, the vaginal smear was analyzed under light microscope and find out the proportion of three cell types namely nucleated epithelial cells, cornified epithelial cells and leucocytes [31,32]. Proestrus was
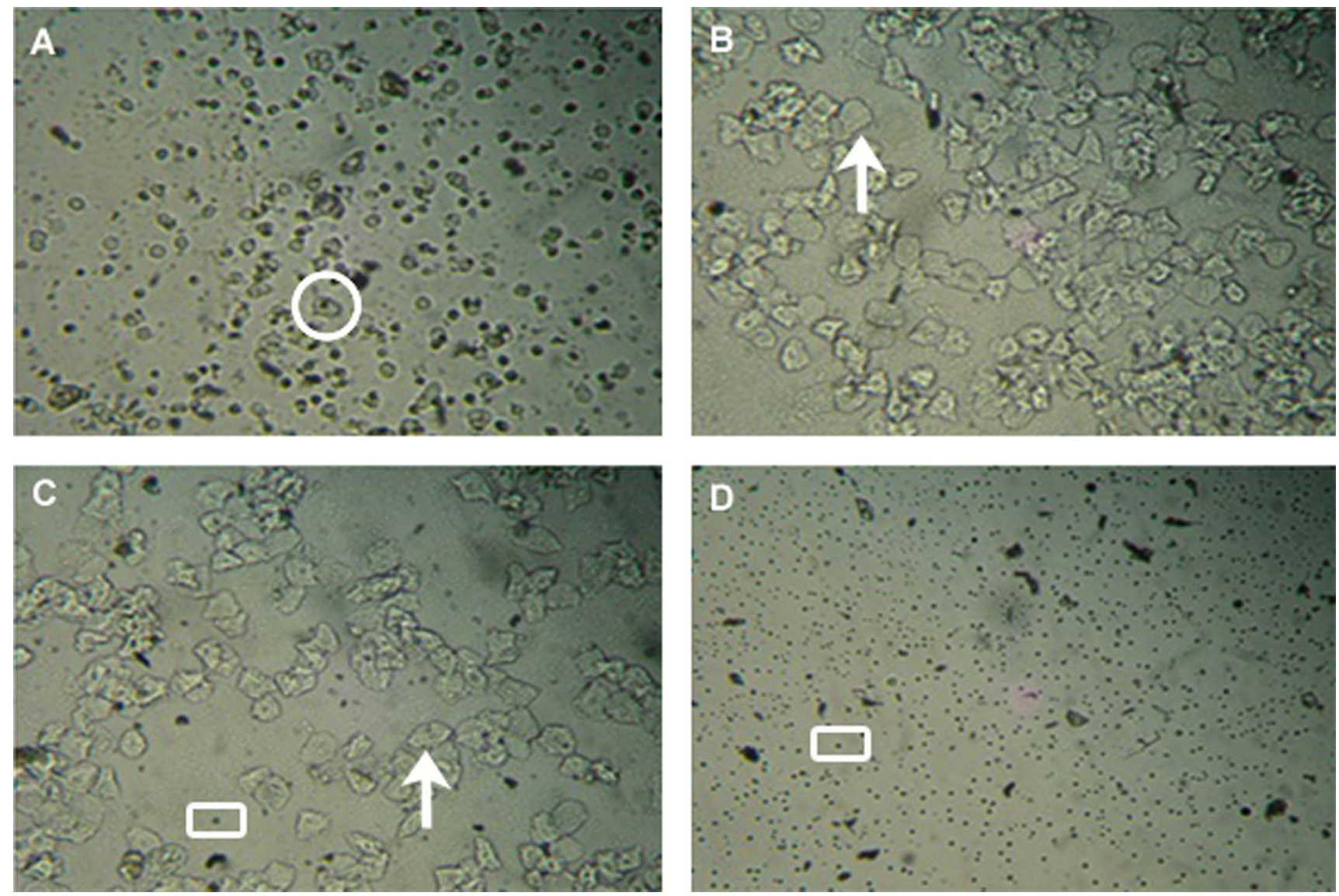

Figure 1. Vaginal cytology as observed in commensal rat at different phases of estrous cycle. The observed estrous cycle phases are (A) Proestrus, (B) Estrus, (C) Metestrus, (D) Diestrus. Nucleated epithelial (circle), cornified epithelial (arrow), leucocytes (Square) were identified in vaginal smear.

doi:10.1371/journal.pone.0071357.g001 


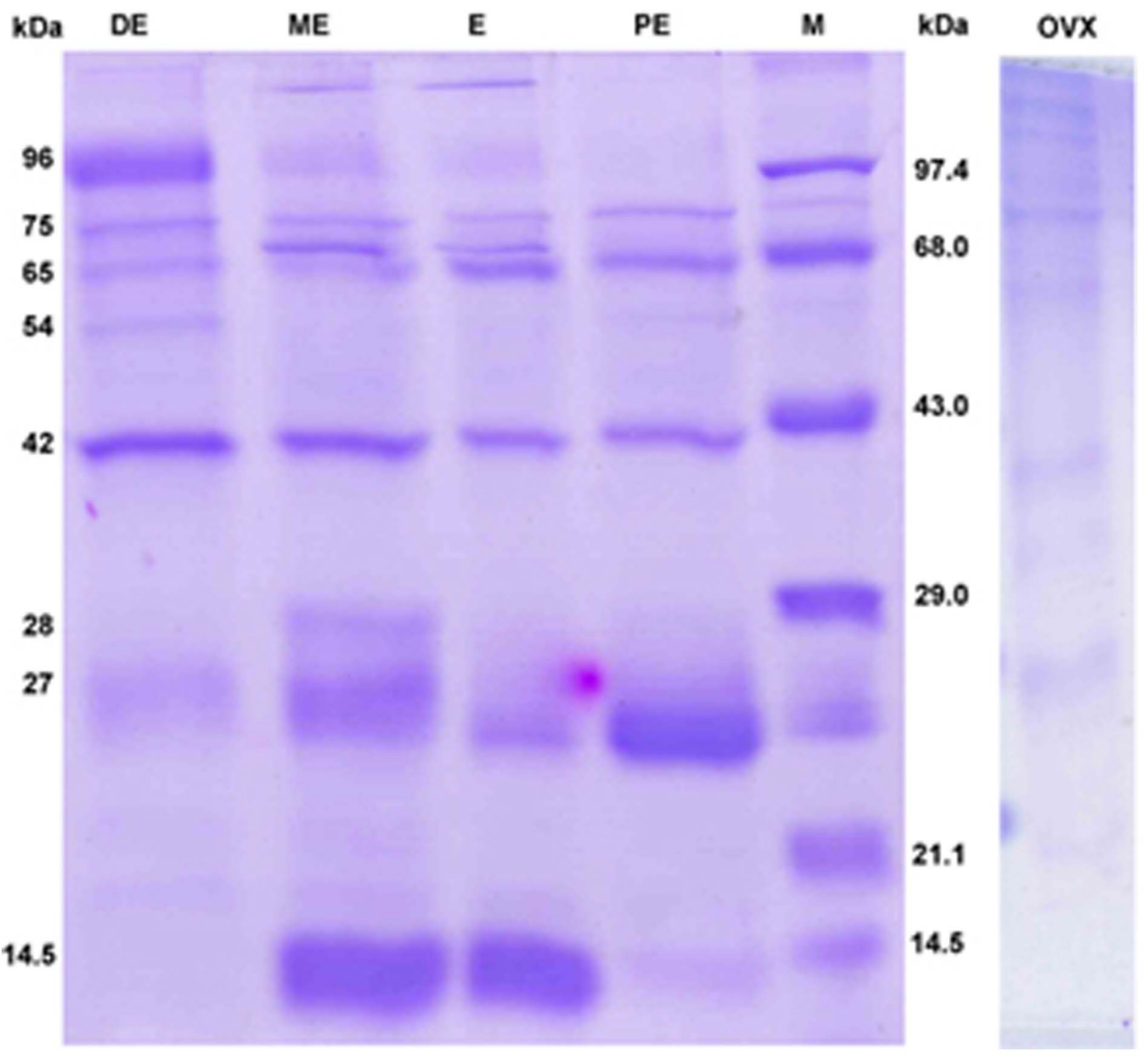

Figure 2. SDS-PAGE urinary protein profile of commensal rat. The estrous cyclic and ovariectomized urinary proteins were separated by $12 \%$ SDS-PAGE and the Lane- M contains $7 \mu$ L of Bangalore Genei protein molecular markers, (PE) Proestrus, (E) Estrus, (ME) Metestrus, (DE) Diestrus, (OVX) Ovariectomized, each lane contains $30 \mu \mathrm{g}$ protein. doi:10.1371/journal.pone.0071357.g002

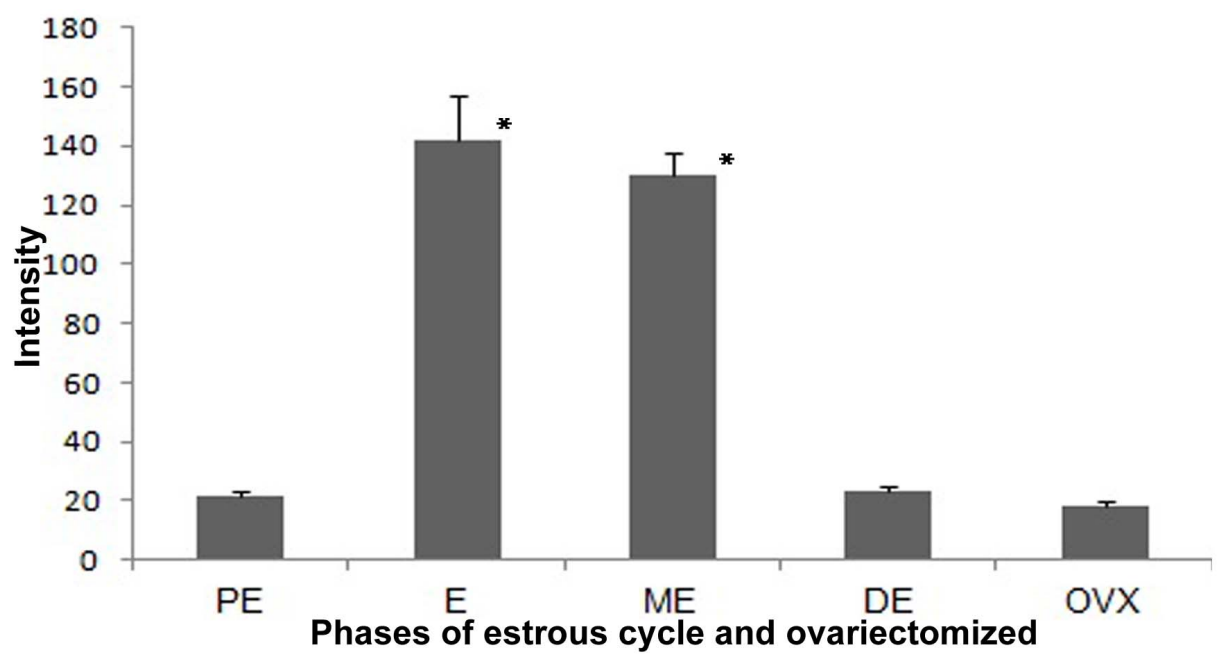

Figure 3. Intensity (band area) of $\mathbf{1 4 . 5} \mathbf{~ k D a}$ protein around estrous cycle and Ovariectomized animal. The intensity of the protein band was compared with estrous phases and ovariectomized animal. The protein intensity significantly high during estrus (E) and metestrus (ME) compared to proestrus (PE), diestrus (DE) and ovariectomized (OVX) using Fisher's least significant difference post-hoc comparisons $\left({ }^{*} p<0.05\right)$. Values are mean \pm SE from six gels (Figure S2).

doi:10.1371/journal.pone.0071357.g003 


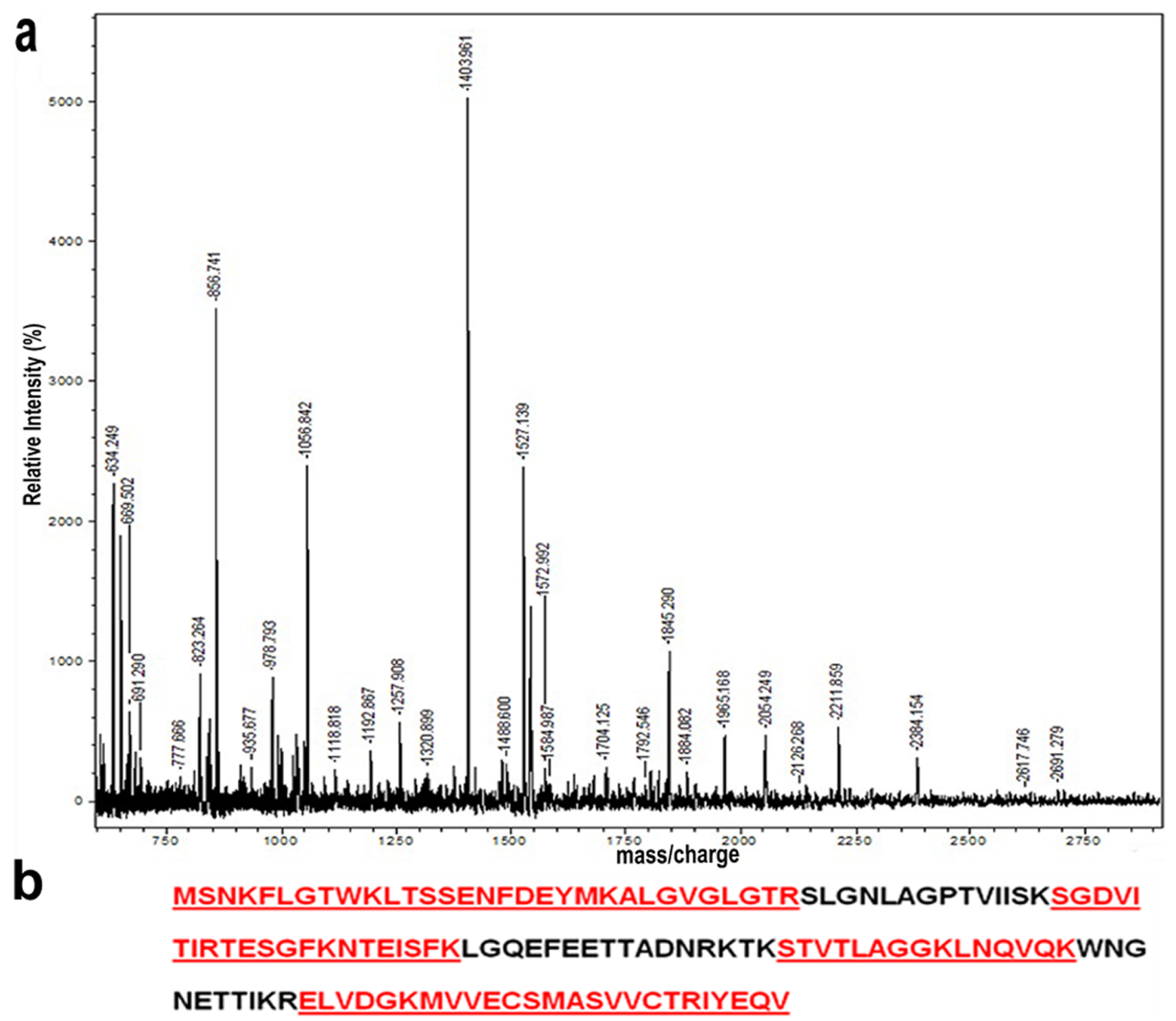

Figure 4. MALDI-mass spectrum and Sequence coverage of $\mathbf{1 4 . 5}$ kDa band. (a) $14.5 \mathrm{kDa}$ protein band was undergone for in-gel tryptic digestion and the spectra was collected form MALDI-MS. Number in the mass spectrum gives precise $\mathrm{m} / \mathrm{z}(\mathrm{M}+\mathrm{H})$ values for detected peptide ion signals. (b) Single letter coded protein sequence was obtained for $14.5 \mathrm{kDa}$ from mascot search. The matched $69 \%$ sequence coverage was highlighted in underlined red colour. doi:10.1371/journal.pone.0071357.g004

indicated when nucleated epithelial cells alone were present; estrus when cornified epithelial cells alone were present; metestrus when both cornified epithelial cells and leucocytes were present; and diestrus when leucocytes alone were present. This assessment was done before and after every urine sample collection.

\section{Vaginal Cytology by SEM (Scanning Electron Microscopy) Analysis}

Based on the cellular constituents in the vaginal smear during estrus and diestrus phases, the cells were subjected to scanning electron microscopic analysis. A cold Field Emission-Scanning Electron Microscope (FE-SEM, 6701 F, JEOL, Japan) at the Center for Nanotechnology and Advanced Biomaterials (CeNTAB), SASTRA University, Thanjavur, India, was used. The spot of smear sample was spread in a glass slide and mounted on to a brass stub using a double sided carbon tape. The samples surface was sputter coated with gold particle in a thin film at a current of $20 \mathrm{~mA}$ for $45 \mathrm{sec}$ to form a conducting layer. A brass stub was loaded into the specimen chamber. An accelerating voltage of $3 \mathrm{kV}$ was used to image the samples at ultra-high vacuum using the secondary electron detector and working distance of 6.5 to $7 \mathrm{~mm}$ [33]. The cells were photographed.

\section{Urine Collection and Sample Preparation}

Urine from females rats $(\mathrm{n}=12)$, which exhibited regular estrous cycle, was collected for over ten consecutive estrous cycles. In order to avoid the contaminants such as hair, dirt and fecal debris, the animals were shifted to specialized metabolism cages (without bedding) for urine collection. The collected samples were immediately filtered though Whatman filter paper and centrifuged at $12,000 \mathrm{rpm}$ for $10 \mathrm{~min}$ at $4^{\circ} \mathrm{C}$, and the clear supernatant was separated. The samples were concentrated using $10 \mathrm{kDa}$ Cen- 
Table 1. Mass values of EULP.

\begin{tabular}{llll}
\hline Start - End & Observed Mass & Expected Mass & Sequence \\
\hline $\mathbf{1 - 1 0}$ & 1211.0410 & 1210.0337 & -.MSNKFLGTWK.L \\
$\mathbf{5 - 2 2}$ & 2211.8590 & 2210.8517 & K.FLGTWKLTSSENFDEYMK.A \\
$\mathbf{2 3 - 3 1}$ & 842.7690 & 841.7617 & K.ALGVGLGTR.S \\
$\mathbf{4 6 - 5 3}$ & 861.2150 & 860.2077 & K.SGDVITIR.T \\
$\mathbf{5 4 - 5 9}$ & 669.5020 & 668.4947 & R.TESGFK.N \\
$\mathbf{5 4 - 6 6}$ & 1488.6000 & 1487.5927 & R.TESGFKNTEISFK.L \\
$\mathbf{8 3 - 9 7}$ & 1543.0430 & 1542.0357 & K.STVTLAGGKLNQVQK.W \\
$\mathbf{1 0 8 - 1 1 3}$ & 660.6750 & 659.6677 & R.ELVDGK.M \\
$\mathbf{1 1 4 - 1 2 7}$ & 1660.1350 & 1639.1277 & K.MVVECSMASVVCTR.T \\
$\mathbf{1 2 8 - 1 3 2}$ & 650.2190 & 649.2117 & R.IYEQV.- \\
\hline
\end{tabular}

Observed and expected masses $(\mathrm{M}+\mathrm{H})$ of $14.5 \mathrm{kDa}$ protein and tryptic digested peptide sequence map by MALDI-TOF/MS, which was retrieved from Mascot database. The matched peptides are bolded in black.

doi:10.1371/journal.pone.0071357.t001

tricon cut-off membrane (GE Biosciences). The concentration of protein was determined according to Bradford [34].

\section{Ovariectomy}

Reproductively active female rats $(n=5)$ were anesthetized using diethyl ether. The abdominal region was shaved and wiped with ethanol. A single midline incision in lower abdominal region was made using a surgical blade. The oviducts were pulled out and

Table 2. EULP sequence information.

\begin{tabular}{|c|c|c|}
\hline Amino acid & No of residues & Percentage of residues \\
\hline Ala (A) & 5 & 3.80 \\
\hline $\operatorname{Arg}(\mathrm{R})$ & 5 & 3.80 \\
\hline Asn (N) & 8 & 6.10 \\
\hline Asp (D) & 4 & 3.00 \\
\hline Cys (C) & 2 & 1.50 \\
\hline $\mathrm{Gln}(\mathrm{Q})$ & 4 & 3.00 \\
\hline Glu (E) & 11 & 8.30 \\
\hline Gly (G) & 13 & 9.80 \\
\hline $\mathrm{His}(\mathrm{H})$ & 0 & 0.00 \\
\hline Ile (I) & 7 & 5.30 \\
\hline Leu (L) & 10 & 7.60 \\
\hline Lys (K) & 12 & 9.10 \\
\hline Met (M) & 4 & 3.00 \\
\hline Phe (F) & 5 & 3.80 \\
\hline Pro $(P)$ & 1 & 0.80 \\
\hline Ser (S) & 11 & 8.30 \\
\hline Thr (T) & 15 & 11.40 \\
\hline $\operatorname{Trp}(\mathrm{W})$ & 2 & 1.50 \\
\hline Tyr (Y) & 2 & 1.50 \\
\hline Val (V) & 11 & 8.30 \\
\hline Pyl (O) & 0 & 0.00 \\
\hline $\operatorname{Sec}(U)$ & 0 & 0.00 \\
\hline
\end{tabular}

both ovaries were removed. Afterwards the inner and outer skin layers were stitched [35]. Three weeks later, the vaginal cytology was observed for loss of cyclicity. Urine was collected from the ovariectomized rats to find the expression of the protein of interest.

\section{Sodium Dodecyl Sulphate Poly Acrylamide Gel Electrophoresis (SDS-PAGE)}

In the present investigation, 12\% SDS-PAGE was carried out with female rat urinary protein from each phase of the estrous cycle, and from ovariectomized rat (30 $\mu \mathrm{g}$ protein in each). A medium range molecular weight marker set (Bangalore Genei) was used for the molecular weight reference. The electrophoresis was done at constant voltage $(50 \mathrm{~V})$ at room temperature.

Detection of Protein by Coomassie Brilliant Blue Solution

After completing the electrophoresis, the gels were rinsed with distilled water for $2 \mathrm{~min}$ and stained with $0.5 \%$ Coomassie brilliant blue R-250 in 40\% methanol and 10\% acetic acid, at room temperature, for $2 \mathrm{hrs}$. The gels were then destained in a solution containing $40 \%$ methanol and $10 \%$ acetic acid until background became clear. Finally, the gels were washed with Milli-Q water and utilized for further analysis. The intensity and molecular weight of the protein bands in the gels were identified using gel documentation (Quantity One software, Bio Rad, CA, USA). The band area was measured in pixels.

\section{Trypsin Digestion}

The trypsin in-gel digestion of urinary polypeptides was conducted according to Rajkumar et al. [5]. The differentially expressed bands were removed from the SDS-PAGE using a thin glass pipette and placed into microcentrifuge tubes. The gel plug was destained using $100 \mu \mathrm{L}$ of $50 \mathrm{mM}$ ammonium bicarbonate and $50 \%(\mathrm{v} / \mathrm{v})$ acetonitrile $(1: 1)$ and incubated at $37^{\circ} \mathrm{C}$ for $30 \mathrm{~min}$. This step was repeated until no stain was visible in the gel spot. Gel pieces were sliced into small cubes, and placed in $1.5 \mathrm{~mL}$ tube pre washed with ethanol.

The plugs were then incubated at $37^{\circ} \mathrm{C}$ with $50 \mu \mathrm{L}$ of $10 \mathrm{mM}$ DTT for $30 \mathrm{~min}$; the DTT was discarded, and $50 \mu \mathrm{L}$ of $55 \mathrm{mM}$ iodoacetamide was added to each tube and incubated for $1 \mathrm{hr}$ at room temperature in the dark. The iodoacetamide solution was discarded and the plugs were washed twice as above before being dehydrated in $100 \%$ acetonitrile and then rehydrated in $9 \mu \mathrm{L}$ of $50 \mathrm{mM}$ ammonium bicarbonate. After $30 \mathrm{~min}$ incubation at room 


$\begin{array}{ccccccc}10 & 20 & 30 & 40 & 50 & 60 & 70 \\ \text { MSNKFLGTWKLTSSENFDEYMKALGVGLGTRSLGNLAGRTVI ISKSGDVITIRTESGFKNTEISFKLGQE }\end{array}$
hhhhhhcceeecchhhhhhhhhhhtcchhhhhhcccccceeeect tceeeeeecccccceeeeeccc FEETTADNRKTKSTVTLAGGKLNQVQKWNGNETTIKRELVDGKMVVECSMASVVCTRIYEQV hhhhccttcceeeeeett tceeeeccccceeeehhhcttceeeeectteeeeeehhh

Figure 5. Secondary structure of EULP. Secondary structure of $14.5 \mathrm{kDa}$ protein was analyzed by SOPMA tool. The total sequence length was 132 and the sequence contains extended strand (Ee), alpha helix (Hh), random coil (Cc) and beta turn (Tt). doi:10.1371/journal.pone.0071357.g005

temperature in the dark, the gel particles were washed with $50 \%$ acetonitrile in $0.1 \mathrm{M}$ ammonium bicarbonate and dried in a Speed-Vac evaporator [36]. The dried gel pieces were swollen in a minimum volume of a $10 \mu \mathrm{L}$ digestion buffer that contained $50 \mathrm{mM}$ ammonium bicarbonate, $5 \mathrm{mM}$ calcium chloride, and $100 \mathrm{ng}$ of trypsin in order to keep the gel pieces wet during enzymatic cleavage at $37^{\circ} \mathrm{C}$ for overnight.

\section{MALDI-TOF/Mass Spectrometry}

The sample (tryptic fragmented) was prepared by mixing equal amounts (2:2) of peptide mixture with the matrix solution $(\alpha-$ Cyano-4-hydroxycinnamic acid) saturated with $0.1 \%$ TFA and acetonitrile $(1: 1)$. Then the samples were analyzed in Ultraflex spectrometer (Brukar Daltonics, Billericia, MA, USA and Bremen, Germany) with reflection mode a delay time of $90 \mathrm{~ns}$ and $25 \mathrm{kV}$ accelerating voltage in the positive ion mode. To improve the signal to noise ratio summation of 300 laser shots were taken for each spectrum. External calibration was done using peptide I calibration standard with masses ranging from 1046-3147 Da. Mass spectra were acquired by selecting the precursor mass with 8 Da window.

\section{Database Analysis}

The collected mass spectra were processed by FLEX analysis software and the mono- isotopic peptide masses were assigned and used in the database search. The protein identification was accomplished using MASCOT search (http//www.matrixscience. com). Scores $>63$ were considered to be significant $(p<0.05)$. The primary sequence detected in female rat urinary protein was retrieved from NCBI. The amino acid composition and physiochemical properties viz., molecular weight, theoretical pI, amino acid length, atomic composition, estimated half life, instability index, extinction coefficient, aliphatic index, and grand average of hydropathicity (GRAVY) were computed by PROTPARAM tool available in EXPASY website (http://web.expasy.org/ protparam/). Further analysis for finding domain region and motif in the primary sequence was done by DIAL server (http:// caps.ncbs.res.in/DIAL/home.html) [37]. Prediction of helix, sheets and coils in the secondary structure of the lipocalin was carried out using Self-optimized prediction method with multiple alignments (SOPMA) (http://npsa-pbil.ibcp.fr/cgi-bin/ npsa_automat.pl?page =/NPSA/npsa_sopma.html) [38].
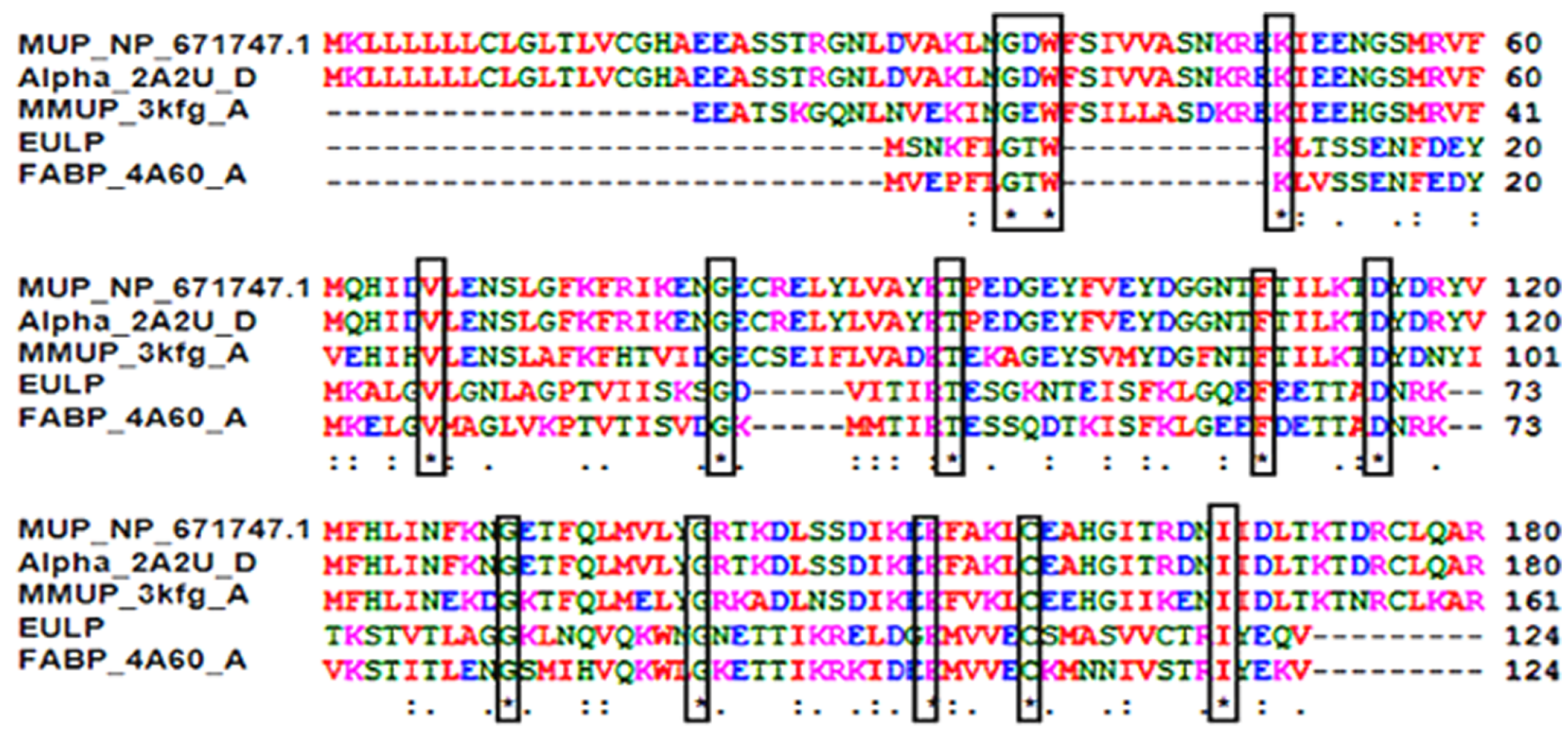

$\begin{array}{ll}\text { MUP_NP_671747.1 G } 181 \\ \text { AIpha_2A2U_D } & \text { G } 181 \\ \text { MMUP_3kfg_A } & \text { E } 162 \\ \text { EULP } & - \\ \text { FABP_4A60_A } & -\end{array}$

Figure 6. MSA analysis of EULP with other lipocalin proteins. MSA alignment made by using major urinary protein (Gene ID: NP_671747.1) followed by a-2u globulin (PDB code: $2 A 2 U$ ), major mouse urinary protein (PDB code: 3KFG), fatty acid binding protein (PDB code: 4A60) and EULP. EULP have 12 conserved motif $\left({ }^{*}\right)$ denoted in the boxes, $-\mathrm{GXW}$ - motif region and many identical residue (:). doi:10.1371/journal.pone.0071357.g006 

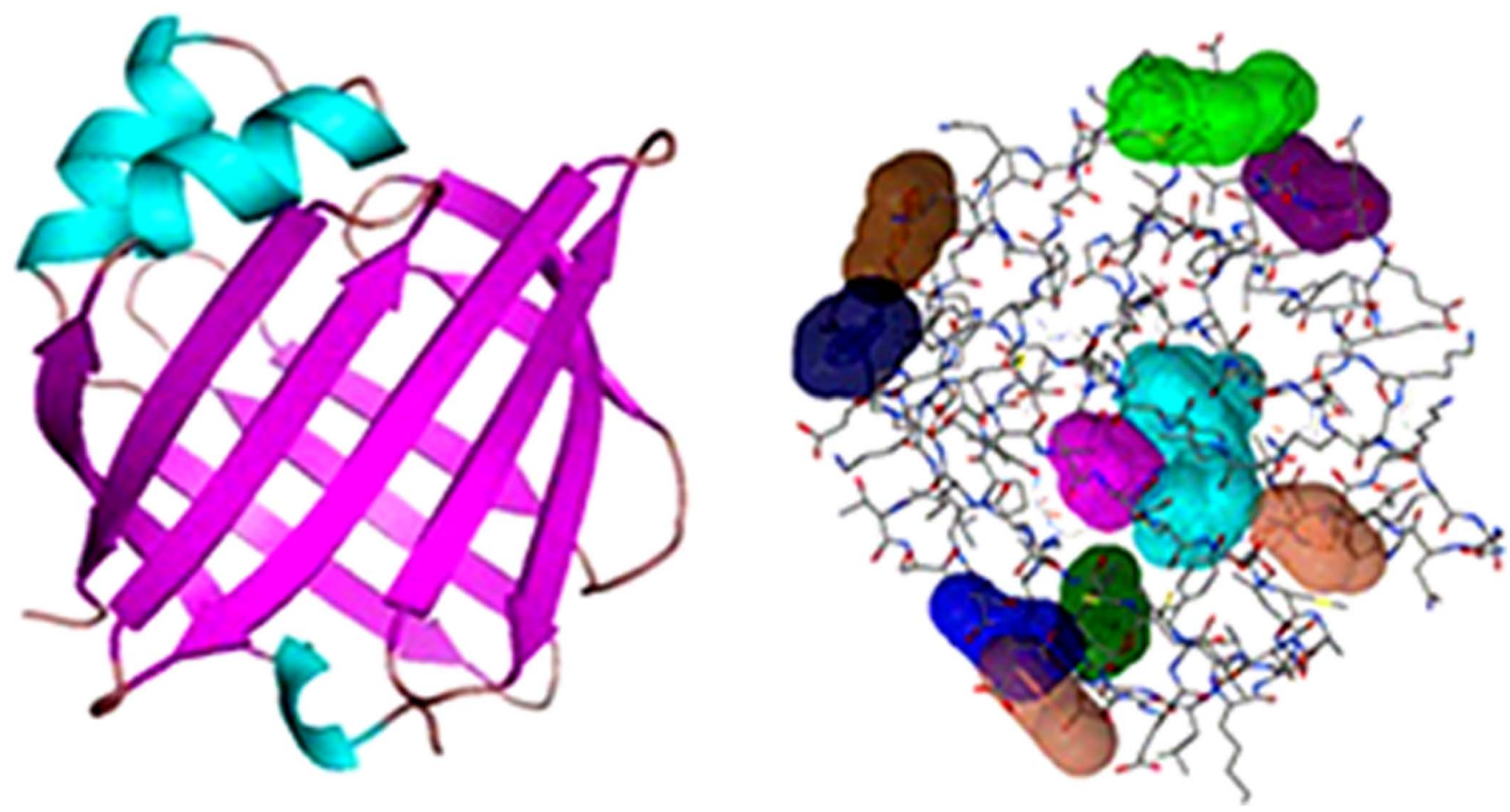

Figure 7. Homology modeling and binding site prediction for EULP. (a) EULP secondary structure was model by (PS) ${ }^{2}$-V 2 and visualized in PyMol. The model represents the alpha helices and beta sheets were linked with coils and look like TIM Barrel structure. (b) Binding sites was analyzed by $\mathrm{Q}$-SiteFinder and the protein expresses 10 different binding sites (different colours).

doi:10.1371/journal.pone.0071357.g007

\section{Molecular Modeling and Structural Validation}

The lipocalin sequence was compared with the other urinary lipocalin proteins and fatty acid binding protein collected from

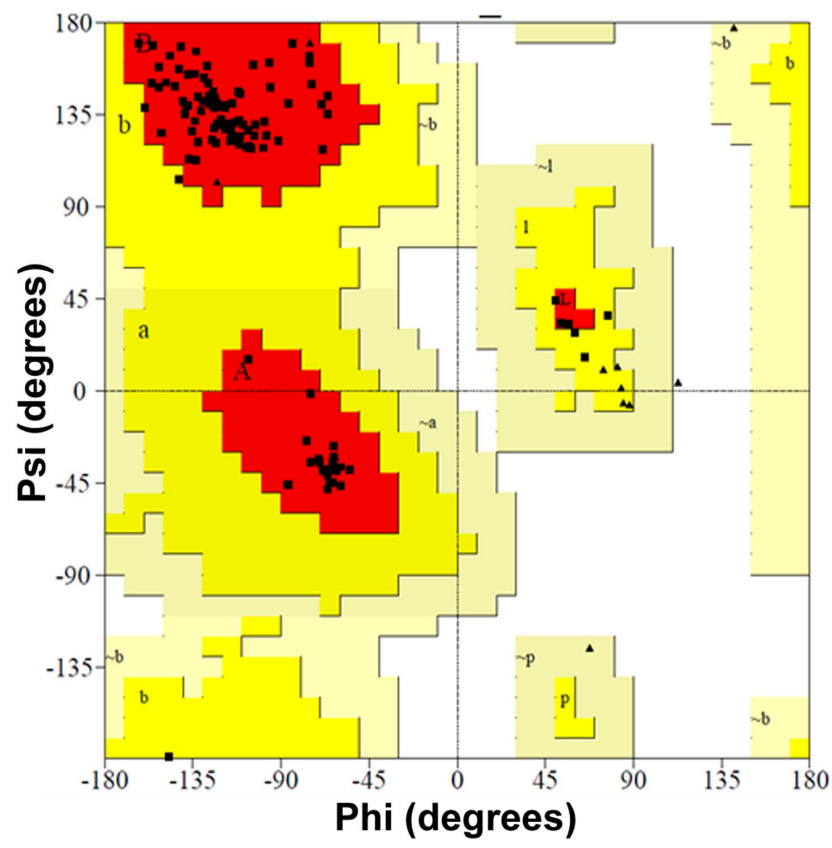

Figure 8. Structure validation of EULP. The developed EULP model was validated by Ramachandran Plot using PROCHECK tool in SAVeS server. The result showed that $95.7 \%$ residues were present in most favoured regions and $4.3 \%$ residues in the additional allowed regions. doi:10.1371/journal.pone.0071357.g008 non-redundant database i.e., NCBI (www.ncbi.nlm.nih.gov) through multiple sequence alignment (MSA) executed by ClustalW2 (http://www.ebi.ac.uk/Tools/msa/clustalw2/), which is available in EMBL-EBI website and Expasy bioinformatics resource portal [39].

Comparative modeling of lipocalin was done for determining the three dimensional structure and binding sites. SWISSMODEL (http://swissmodel.expasy.org/) [40] is a database for constructing the homology model of protein or DNA with computational approach to predict the best hit template for the unknown or desired sequence. The lipocalin family protein was used to identify the best template using template identification tool in the SWISS-MODEL database. Molecular modeling creates an accurate model of the lipocalin sequence by comparing the best hit template. The (PS) ${ }^{2}-\mathrm{V} 2$ is a molecular modeling server that consists of MODELLER package was used to constructing three dimensional structure of lipocalin protein through automated method (http://ps2v2.life.nctu.edu.tw/) [41].

Model validation carried out by SAVeS server, in which PROCHECK tool was selected (http://www.ebi.ac.uk/thorntonsrv/software/PROCHECK/) [42]. Computationally calculated phi/psi values and allowed and disallowed regions of desired protein model were made using Ramachandran plot, which is mainly performed for predicting range of helices, strands and coils of furnished model. Hence, the visualization of the constructed model was performed using PyMol software (V0.99) (http://www. pymol.org/). The binding sites were predicted using Q-SiteFinder server (http://www.modelling.leeds.ac.uk/qsitefinder/) [43].

\section{Statistics}

The band intensity of estrous cycle and ovariectomized animal urinary protein was analyzed using one-way analysis of variance (ANOVA) by SPSS version 16 (SPSS Inc., Cary, NC, USA). 


\section{Results and Discussion}

\section{Characterization of Vaginal Smear and SEM Analysis}

Proestrus was identified from the presence, in vaginal smear, of round, nucleated epithelial cells with granular structures (Figure 1A). The first onset of this feature identified day one of the estrous cycle. The proestrus most invariably commenced at early morning, from 5 to $8 \mathrm{am}$, and it was never delayed beyond the evening of day of first appearance. During transition to estrus the vaginal smear showed a characteristic cluster of cornified epithelial cells. At the end of the estrus, the cells changed in appearance to needle-like due to losing of content. In as much as one estrous cycle covered five days, estrus lasted mostly for only one day, and very occasionally two days (Figure 1B). Metestrus preceded diestrus and during this time the smear had fewer cornified epithelial cells but mostly leucocytes. This transition phase lasted only few hours of the entire cycle (Figure 1C). When the smear showed exclusively leucocytes populations the day was considered as diestrus. This condition continued for two or three days in each cycle (Figure 1D). By the close of diestrus, in addition to the leucocytes, a few epithelial cells appeared in the smear. SEM analysis revealed the presence of cornified cells during estrus and leucocytes during diestrus (Figure S1).

\section{SDS-PAGE of Rat Urinary Protein}

The urinary protein profiles of rat during the four phases of estrous cycle were compared. Irrespective of the phases in the estrous cycle, totally eight polypeptides were expounded by Coomassie brilliant blue staining of the gels. The molecular mass of these polypeptides ranged from 14.5 to $96 \mathrm{kDa}$ (Figures 2 and $\mathrm{S} 2$ ). The molecular weights were identified through medium range molecular weight markers. The polypeptides of high molecular weight did not differ much between phases. On the other hand the intensity of low molecular weight polypeptides differed between the phases. The $28 \mathrm{kDa}$ polypeptide appeared only during metestrus. The $27 \mathrm{kDa}$ protein was highly expressed during proestrus, and gradually decreased through the subsequent phases. It is known that pheromonal communications are mediated by lipocalin proteins of molecular mass, from 17 to $30 \mathrm{kDa}[9,12,44]$. In the present study, $14.5 \mathrm{kDa}$ protein appeared faintly during proestrus, reaching the highest intensity during estrus and metestrus $(p<0.05)$ and then it almost disappeared during diestrus. However, in ovariectomized animals $14.5 \mathrm{kDa}$ protein was almost absent (Figures 2, 3, and S2).

Recently, Roberts et al. [16] have reported that $18.89 \mathrm{kDa}$ involatile protein in male mouse urine, darcin, acts as a sex attractant. Darcin is also actively involved in spatial learning of female mice for individual identification lasting 14 days [45]. This urinary protein, proved to be involved as signaling pheromone, is first report in rodent chemical communication. It is interesting that a $14.5 \mathrm{kDa}$ protein was identified in the present study in female rat urine, and it was expressed at a significantly higher intensity during estrus and metestrus. It is to be remembered that metestrus is only a transient extension of estrus and is short-lived. Moreover, this protein is expressed poorly in ovariectomized rat urine. Hence, the results convincingly suggest that this protein may signify something special during estrus and may have a role in conspecific communication through pheromonal compounds or it may act as a sex attractant by itself.

\section{MALDI-TOF/MS}

The differentially expressed 14.5, 27, 28 and $96 \mathrm{kDa}$ proteins were excised and subjected to in gel-tryptic digestion followed by peptide mass finger printing (PMF). Good quality MALDI spectra were obtained for $14.5 \mathrm{kDa}$ band (Figure 4a). Polypeptides of MW 27, 28, $96 \mathrm{kDa}$ did not match with any lipocalin family protein (data not included). Further, the monoisotopic mass of $14.5 \mathrm{kDa}$ protein was subjected to MASCOT search to identify the full length sequence. It closely matched with Equus caballus lipocalin family protein with $69 \%$ sequence coverage and three matched peptides (Figure 4b, Table 1). Here-in-after this protein is referred to as estrus urinary lipocalin protein (EULP) of rat. This result is consistent with the earlier reports on lipocalin protein and EULP may be considered as the vehicle for communication through/as a volatile compound from delivery to perception $[5,9,46]$.

\section{Amino Acid Properties of EULP}

The physicochemical properties of EULP were analyzed using the PROTPARAM tool in Expasy bioinformatics resource portal. The EULP showed up to about 132 amino acids, and the total number of atoms in the sequence was 2043. The sequence purified from the lowest molecular weight at $14,491.5$ and the theoretical pI was 8.56. The sequence formula was $\mathrm{C}_{632} \mathrm{H}_{1029} \mathrm{~N}_{173} \mathrm{O}_{203} \mathrm{~S}_{6}$. The EULP sequence contains about 15 positively charged residues (Arg and Lys combined) and 15 negatively charged residues (Asp and Glu combined). The aliphatic index was calculated as 78.18. The instability index of the protein was computed as 32.20 and stable. The grand average of hydropathicity (GRAVY) was calculated as -0.326 , and it is indicative of hydrophilic and soluble protein. Proline showed single residue in minimum number $(0.80 \%)$, and the single largest number of amino acid present in the sequence was threonine (11.40\%). However, histidine $(0.00 \%)$, pyrrolysine $(0.00 \%)$ and selenocysteine $(0.00 \%)$ were totally absent (Table 2).

\section{Domain Identification by DIAL Server}

The domain is an important element of protein, which can provide for activation of the structural and functional expression in a cell. The EULP sequence was submitted for the identification of domain present in the entire sequence. Six significant functional motifs were identified in EULP sequence; they are an $\mathrm{N}$ glycosylation site, a tyrosine sulfation site, seven protein kinase $\mathrm{C}$ phosphorylation site, a casein kinase II phosphorylation site, two $\mathrm{N}$-myristoylation site, and a cytosolic fatty-acid binding protein site [37] (Table S1).

\section{Secondary Structure Prediction by SOPMA}

SOPMA is fully based on the homologue method as proposed by NPS@ (Network Protein Sequence Analysis)web server. EULP sequence having extended strand (Ee) was found most frequent $(37.12 \%)$, followed by random coil (Cc) that was $28.79 \%$ and alpha helix $(\mathrm{Hh})$ that was $25.00 \%$. The beta turn $(\mathrm{Tt})$ was found to least frequent, $9.09 \%$ (Figure 5).

\section{Multiple Sequence Alignment by ClustalW2}

The EULP sequence were aligned with MMUP (Mouse major urinary protein_3kfg_A), MUP (Major urinary protein_NP_671747.1), $\alpha 2 \mathrm{u}$ globulin (A2u_2A2U_D) and a fatty acid binding protein (FABP_4A60_A), respectively, and showed the maximum numbers of identical residues and also represented the most frequent numbers of conserved residues (Figure 6) [12]. Lipocalin members have some specific motifs within the family [19]. Most probably, the sequence of EULP has a significant lipocalin motif (i.e. -GXW- region) with the other urinary protein of rodents and fatty acid binding protein. Hence, the -GXW-is the major reported feature of lipocalin protein [47] and significantly present in the EULP. This is the ultimate proof that the EULP 
fulfills the requirements to be identified as a lipocalin super family protein, and it may be associated with the delivery of a chemosignal during the estrus phase.

\section{Homology Modeling and Structure Validation}

Most similar sequences were analyzed and the highest hit was used as a template for the EULP made by SWISS-MODEL database. The first hit from the $\mathrm{HH}$ search was human testisspecific fatty acid binding protein (PDB code: 4A60_HTSFABP). The EULP and template were matched with highest probability, the aligned residues are 131, E-value is $9.8 \mathrm{e}-45$, the sequence identity is $63 \%$ and alignment score is 292.88 .

The EULP model was created using protein structure prediction server $(\mathrm{PS})^{2}-\mathrm{V} 2$ and this is the automated web server by the MODELLER tool. The model contains the highest sequence alignment $(99.24 \%)$ and the identity was $63.36 \%$. The structure resembled the continuous beta parallel strands (TIM Barrel) and alpha helices with inter connecting loops (Figure 7a). As earlier reports showed that the lipocalin members share structural similarity with functional motifs [19]. Then, the furnished EULP model was analyzed for identificaiton of binding site using the QSiteFinder tool, in which the model depicted the ten different binding sites (Figure 7b). Further, the EULP model was subjected for structure validation using phi/psi value obtained by Ramachandran plot present in the PROCHEK tool from the SAVeS server. Validation of EULP showed that the residues in most favoured regions got nearer $95.7 \%$, and residues in additional allowed regions close to $4.3 \%$. The best model would be anticipated to have over $90 \%$ in the most favoured regions and, thus, in EULP having more than this favoured regions (Figure 8), gets validated as belonging to lipocalin superfamily protein.

Hurst et al. [48] furnished a detailed account about improvement of longivity of the pheromonal compounds in the environment through the urine scent marking of male mouse using lipocalin as the binding protein. We reported the compounds 1chlorodecane, a predominant urinary volatile [12], and farnesol of preputial gland [5] bound with $17 \mathrm{kDa}$ and $21 \mathrm{kDa}$ lipocalin protein, respectively, in male commensal rat. Aphrodisin, a lipocalin present in hasmster vaginal secretion, has been shown to serve a dual role of (a) by itself functiong as a pheromone, and (b) binding with pheromonal compound(s), thereby influencing the pheromonal effects [49]. Since these earlier studies provide elaborate information about bound form of lipocalin, and also lipocalins by themselves are capable of acting as pheromones, the $14.5 \mathrm{kDa}$ lipocalin protein substantiated so in the sequence similarity and the structural features, identified in the urine of female commensal rat may have functional significance in sexual communication. Importantly, its high levels of prevalence during estrus would reveal the readiness of the female to entertain the male by way of mating behavior and coitus.

\section{References}

1. Breer H (1994) Odor recognition and second messenger signaling in olfactory receptor neurons. Semin Cell Biol 5: 25-32.

2. Martinez GF, Martinez RJ, Agustin C, Martinez HJ, Novejarque A, et al. (2009) Refining the dual olfactory hypothesis: Chemosignal reward and odour experience. Behav Brain Res 200: 277-286.

3. Cavaggioni A, Mucignat-Caretta C (2000) Major urinary proteins, alpha (2U)globulins and aphrodisin. Biochim Biophys Acta 1482: 218-228.

4. Achiraman S, Archunan G (2002) Urinay proteins and pheromonal communication in mammals. Indian J Exp Biol 40: 1077-1078.

5. Rajkumar R, Ilayaraja R, Liao CC, Archunan G, Achiraman S, et al. (2010) Detection of alpha $(2 \mathrm{u})$-globulin and its bound putative pheromones in the preputial gland of the Indian commensal rat (Rattus rattus) using mass spectrometry. Rapid Commun Mass Spectrom 24: 721-728.

\section{Conclusions}

In this study, we have reported for the first time the presence of lipocalin family protein in urine of a female rodent. The expression of this protein in the urine has a correlation with the phases in the estrous cycle, this being the highest during estrus and metestrus. That the protein we dealt with here is a lipocalin is established from homology similarity, sharing $\beta$-parallel structures with linked $\alpha$-helices and most reported -GXW- motif region. We suggest that the $14.5 \mathrm{kDa}$ lipocalin family rodent urinary protein might be involved as the shuttle for chemosignal communication, probably inviting the counterpart. The present finding will have far reaching implications in pheromone biology, such as search for female urinary lipocalin family protein in other rodents and other mammals as well and application in pheromone trap for rodents.

\section{Supporting Information}

Figure S1 Vaginal cytology using SEM analysis. The vaginal secretion was smeared and observed the presence of cells through SEM. Estrus (cornified epithelial cell) and Diestrus (leucocytes cell), the arrow indicates the respective cells.

(TIF)

Figure S2 SDS-PAGE of commensal rat urinary protein. The figures indicate the estrous cycle urinary protein expression of three individual female rat over two cycles. (PE) Proestrus, (E) Estrus, (ME) Metestrus, (DE) Diestrus. A-1, 2 (Animal 1, cycle 1 and 2), B-1, 2 (Animal 2, cycle 1 and 2), C-1, 2 (Animal 3, cycle 1 and 2). Note: Animal 1, cycle 2 gel image is given as representative gel in the mauscript.

(TIF)

Table S1 EULP functional motif sites. Functional motif site of EULP was predicted by DIAL server.

(DOCX)

\section{Acknowledgments}

We thank Prof. M.A. Akbarsha, Director \& Chair, Mahatma Gandhi Doerenkamp Centre, Bharathidasan University, Tiruchirappalli, India for the critical reading of the manuscript, and Prof. Dipankar Chatterje, Molecular Biophysics Unit and Proteomics Facility Center, Indian Institute of Science, Bangalore, for help in MALDI-TOF/MS analysis. The facility availed through UGC-SAP and DST-PURSE is acknowledged. SM thanks Council for Scientific and Industrial Research (CSIR), New Delhi, for the award of Senior Research Fellowship.

\section{Author Contributions}

Conceived and designed the experiments: SM DR GA. Performed the experiments: SM GS AA. Analyzed the data: SM DR RLR. Contributed reagents/materials/analysis tools: GA. Wrote the paper: SM DR GA.

6. Böcskei Z, Groom CR, Flower DR, Wright CE, Phillips SE, et al. (1992) Pheromone binding to two rodent urinary proteins revealed by X-ray crystallography. Nature 360: 186-188.

7. Flower DR, North AC, Sansom CE (2000) The lipocalin protein family: structural and sequence overview. Biochim Biophys Acta 1482: 9-24.

8. Ma W, Wiesler D, Novotny MV (1999) Urinary volatiles of the deer mouse (Peromyscus maniculatus) pertaining to gender and age. J Chem Ecol 25: 417-431.

9. Novotny MV, Ma W, Wiesler D, Zidek L (1999) Positive identification of the puberty-accelerating pheromone of the house mouse: the volatile ligands associating with major urinary protein. Proc R Soc Lond B Biol Sci 266: 2017 2022

10. Beynon RJ, Hurst JL (2003) Multiple roles of major urinary proteins in the house mouse, Mus domesticus. Biochem Soc Trans 31: 142-146. 
11. Robertson DHL, Beynon RJ, Evershed RP (1993) Extraction, characterization and analysis of two pheromonally active ligands associated with major urinary protein of house mouse (Mus musculus). J Chem Ecol 19: 1405-1415.

12. Rajkumar R, Ilayaraja R, Mucignat C, Cavaggioni A, Archunan G (2009) Identification of alpha2u-globulin and bound volatiles in the Indian common house rat (Rattus rattus). Indian J Biochem Biophys 46: 319-324.

13. Marchlewska-koj A (1977) Pregnancy block elicited by urinary proteins of male mice. Biol Reprod 17: 729-732.

14. Mucignat-Caretta C, Caretta A, Cavaggioni A (1995) Acceleration of puberty onset in female mice by male urinary proteins. J Physiol 486: 517-522.

15. Singer AG, Macrides F, Clancy AN, Agosta WC (1986) Purification and analysis of proteinaceous aphrodisiac pheromone from hamster vaginal discharge. J Biol Chem 261: 13323-13326.

16. Roberts SA, Simpson DM, Armstrong SD, Davidson AJ, Robertson DH, et al. (2010) Darcin: a male pheromone that stimulates female memory and sexual attraction to an individual male's odour. BMC Biol 8: 75-95.

17. Beynon RJ, Hurst JL (2004) Urinary proteins and the modulation of chemical scents in mice and rats. Peptides 25: 1553-1563.

18. Sharrow SD, Novotny MV, Stone MJ (2003) Thermodynamic analysis of binding between mouse major urinary protein-I and the chemosignal 2-secbutyl-4, 5-dihydrothiazole. Biochemistry 42: 6302-6309.

19. Flower DR (1996) The lipocalin protein family: structure and function. Biochem J 318: 1-14.

20. Cowan SW, Newcomer ME, Jones TA (1990) Crystallographic refinement of human serum retinol binding protein at 2A resolution. Proteins 8: 44-61.

21. Brownlow S, Morais Cabral JH, Cooper R, Flower DR, Yewdall SJ, et al. (1997) Bovine beta-lactoglobulin at $1.8 \mathrm{~A}$ resolution-still an enigmatic lipocalin. Structure 5: 481-495.

22. Huber R, Schneider M, Mayr I, Muller R, Deutzmann R, et al. (1987) Molecular structure of the bilin binding protein (BBP) from Pieris brassicae after refinement at $2.0 \AA$ resolution. J Mol Biol 198: 499-513.

23. Brennan PA, Keverne EB (2004) Something in the air? New insights into mammalian pheromones. Curr Biol 14: 81-89.

24. Selvaraj R, Archunan G (2002) Chemical identification and bioactivity of rat (Rattus rattus) urinary compounds. Zool Stud 41: 127-135.

25. Achiraman S, Archunan G (2006) 1-iodo 2 methylundecane, a putative estrusspecific urinary chemo-signal of female mouse (Mus musculus). Theriogenology 66: 1913-1920.

26. Sankar R, Archunan G (2008) Identification of putative pheromones in bovine (Bos taurus) faeces in relation to estrus detection. Anim Reprod Sci 103: 149-153.

27. Dehnhard M, Claus R, Pfeiffer S, Schopper D (1991) Variation in estrus-related odors in the cow and its dependence on the ovary. Theriogenology 35: 645-652.

28. Rajanarayanan S, Archunan G (2004) Occurrence of flehmen in male buffaloes (Bubalus bubalis) with special reference to estrus. Theriogenology 61: 861-866.

29. Rajanarayanan S, Archunan G (2011) Identification of urinary sex pheromones in female buffaloes and their influence on bull reproductive behaviour. Res Vet Sci 91: 301-305.

30. Rasmussen LE, Lee TD, Zhang A, Roelofs WL, Daves GD (1997) Purification, identification, concentration and bioactivity of (Z)-7-dodecen-l-yl acetate: sex pheromones of the female Asian Elephant, Elephas maximus. Chem Senses 22: 417-437.
31. Archunan G, Domnic CJ (1990) Stud male protection of implantation in fooddeprived mice: evaluation of the involvement of olfactory-vomeronasal Systems. Exp Clin Endocrinol 96: 30-36.

32. Byers SL, Wiles MV, Dunn SL, Taft RA (2012) Mouse estrous cycle identification tool and images. PLoS One 7: e35538.

33. Yandrapalli N, Rajan KS (2012) One-pot Synthesis of oil dispersible ultra fine manganese (II) oxide nanoparticles. Asian J Sci Res 5: 228-237.

34. Bradford MM (1976) A rapid and sensitive method for the quantitation of microgram quantities of protein utilizing the principle of protein-dye binding. Anal Biochem 72: 248-254.

35. Estrada-Camarena E, Fernandez-Guasti A, Lopez-Rubalcava C (2003) Antidepressant-like effect of different estrogenic compounds in the forced swimming test. Neuropsychopharmacology 28: 830-838.

36. Shevchenko A, Wilm M, Vorm O, Mann M (1996) Mass spectrometric sequencing of proteins silver-stained polyacrylamide gels. Anal Chem 68: 850858.

37. Pugalenthi G, Archunan G, Sowdhamini R (2005) DIAL: a web-based server for the automatic identification of structural domains in proteins. Nucleic Acids Res 33: $130-132$.

38. Geourjon C, Deléage G (1995) SOPMA: significant improvements in protein secondary structure prediction by consensus prediction from multiple alignments. Comput Appl Biosci 11: 681-684.

39. Thompson JD, Higgins DG, Gibson TJ (1994) CLUSTAL W: improving the sensitivity of progressive multiple sequence alignment through sequence weighting, position-specific gap penalties and weight matrix choice. Nucleic Acids Res 22: 4673-4680.

40. Arnold K, Bordoli L, Kopp J, Schwede T (2006) The SWISS-MODEL workspace: A web-based environment for protein structure homology modelling. Bioinformatics 22: 195-201.

41. Chen CC, Hwang JK, Yang JM (2009) (PS) ${ }^{2}-\mathrm{v} 2$ : template-based protein structure prediction server. BMC Bioinformatics 10: 366-378.

42. Laskowski RA, MacArthur MW, Moss DS, Thornton JM (1993) PROCHECK: a program to check the stereochemical quality of protein structures. J Appl Cryst 26: 283-291.

43. Laurie ATR, Jackson RM (2005) Q-SiteFinder: an energy-based method for the prediction of protein-ligand binding sites. Bioinformatics 21: 1908-1916.

44. Robertson DHL, Cox KA, Gaskell SJ, Evershed RP, Beynon RJ (1996) Molecular heterogeneity in the major urinary proteins of the house mouse, Mus musculus. Biochem J 316: 265-272.

45. Roberts SA, Davidson AJ, McLean L, Beynon RJ, Hurst JL (2012) Pheromonal induction of spatial learning in mice. Science 338: 1462-1465.

46. Novotny M, Jemiolo B, Harvey S (1990) Chemistry of rodent pheromones, molecular insights into chemical signaling in mammals. In: MacDonald DW, Müller-Schwarze P, Sanders SA, editors. Chemical Signals in Vertebrates 5. Oxford: Oxford University Press. 1-22.

47. Flower DR, North ACT, Attwood TK (1991) Mouse oncogene protein 24p3 is a member of the lipocalin protein family. Biochem Biophys Res Commun 180: 69-74.

48. Hurst JL, Robertson DHL, Tolladay U, Beynon RJ (1998) Proteins in urine scent marks of male house mice extend the longevity of olfactory signals. Anim Behav. 55: 1289-1297.

49. Briand L, Trotier D, Pernollet JC (2004) Aphorodisin, an aphrodisiac lipocalin secreted in hamster vaginal secretions. Peptides 25: 1545-1552. 